\title{
Assessment of Patient Exposure to X-Radiation from SPECT/CT Scanners
}

\author{
Narihiro Hara ${ }^{1,2}$, Masahisa Onoguchi ${ }^{2}$, Kenichi Takenaka $^{3}$, Kousuke Matsubara $^{2}$, Hiroyuki Ujita $^{1}$, and Youichi Kenko ${ }^{1}$ \\ ${ }^{I}$ Department of Radiology, Sumitomo Hospital, Nakanoshima, Kita-ku, Osaka, Japan; ${ }^{2}$ Department of Health Sciences, Graduate \\ School of Medical Sciences, Kanazawa University, Kodatsuno, Kanazawa, Japan; ${ }^{3}$ Department of Radiological Technology, \\ Kanazawa University Graduate School of Medical Sciences, Kodatsuno, Kanazawa, Japan
}

In the operation of any SPECT/CT system, in addition to internal radiation exposure ( $\gamma$-ray) resulting from administration of radiopharmaceuticals, external radiation exposure (x-ray) from the CT device has to be taken into consideration in the light of recommendations from the International Commission on Radiological Protection. These recommendations include justification of practices (the use of radiation produces sufficient benefit to offset any risks caused by the use of radiation), optimization (the incurred exposure by the use of radiation should be kept as low as reasonably achievable), and dose limitation. The internal radiation exposures of each organ after administration of radiopharmaceuticals are calculated by the MIRD Committee method. For example, the internal radiation exposure index for brain perfusion scintigraphy is $0.8 \mathrm{mGy} / 37 \mathrm{MBq}$ for $N$-isopropyl4-iodoamphetamine $\left({ }^{123}\right)$ hydrochloride or $0.19 \mathrm{mGy} / 37 \mathrm{MBq}$ for ethyl cysteinate dimer. On the other hand, the external radiation exposure from a CT device is calculated using the CT dose index volume (CTDIvol) - a measured and calculated value unique to the CT scanner and scan parameters used-and a dose-length product, which is obtained from CT conditions and generally used as a reference value for CT radiation exposure. However, CTDIvol and dose-length product are calculated values unique to each device, not the value of external radiation exposures of each organ. Therefore, we believe that it is necessary to measure the total (internal plus external) radiation exposure dose from CT. In the present study, using an anthropomorphic phantom for deep-body total absorbed dose measurement, we evaluated the radiation exposure doses (organ-absorbed doses) of each organ under various CT conditions. Methods: The radiation exposure doses of each organ were measured by inserting thermoluminescent dosimeter elements into the phantom under various CT conditions. Results: The following were brain radiation exposure doses in the head region. For $90 \mathrm{kVp}$ and $25 \mathrm{mAs}, 1.39 \mathrm{mGy}$ (CTDlvol, $1.8 \mathrm{mGy}$ ), for $90 \mathrm{kVp}$ and $300 \mathrm{mAs}, 17.00$ mGy (CTDlvol, $21.2 \mathrm{mGy}$ ), for $120 \mathrm{kVp}$ and $25 \mathrm{mAs}$, $3.21 \mathrm{mGy}$ (CTDlvol, $3.8 \mathrm{mGy}$ ), for $120 \mathrm{kVp}$ and $300 \mathrm{mAs}, 37.79 \mathrm{mGy}$ (CTDlvol, $47.7 \mathrm{mGy}$ ), for $140 \mathrm{kVp}$ and $25 \mathrm{mAs}, 5.08 \mathrm{mGy}$ (CTDIvol, $5.5 \mathrm{mGy}$ ), and for $140 \mathrm{kVp}$ and 300 mAs, 65.07 mGy (CTDlvol, $65.6 \mathrm{mGy}$ ). The eye radiation exposure doses were as follows. For $90 \mathrm{kVp}$ and $25 \mathrm{mAs}, 1.94 \mathrm{mGy}$ (CTDIvol, $1.8 \mathrm{mGy}$ ), for $90 \mathrm{kVp}$ and $300 \mathrm{mAs}, 20.31 \mathrm{mGy}$ (CTDIvol, $21.2 \mathrm{mGy}$ ), for $120 \mathrm{kVp}$ and $25 \mathrm{mAs}$, 3.71 mGy (CTDIvol, 3.8

Received Feb. 3, 2010; revision accepted May 14, 2010.

For correspondence or reprints contact: Narihiro Hara, Sumitomo Hospital, Nakanoshima, 5-3-20, Kita-ku, Osaka, Japan 530-0005.

E-mail: hara-narihiro@sumitomo-hp.or.jp

COPYRIGHT @ 2010 by the Society of Nuclear Medicine, Inc.
mGy), for $120 \mathrm{kVp}$ and $300 \mathrm{mAs}, 49.72 \mathrm{mGy}$ (CTDlvol, 47.7 $\mathrm{mGy}$ ), for $140 \mathrm{kVp}$ and $25 \mathrm{mAs}, 5.44 \mathrm{mGy}$ (CTDlvol, $5.5 \mathrm{mGy}$ ), and for $140 \mathrm{kVp}$ and $300 \mathrm{mAs}, 69.76 \mathrm{mGy}$ (CTDIvol, $65.6 \mathrm{mGy}$ ). In addition, the radiation exposure doses of the cervical, thoracic, abdominal, and pelvic regions were measured in detail. Conclusion: Our estimated external radiation exposure doses (x-ray) of each organ under various CT conditions, along with the internal radiation exposure doses ( $\gamma$-ray) resulting from the administration of radiopharmaceuticals, seem to be useful as reference values in understanding the radiation exposure doses for performing various nuclear medicine examinations.

Key Words: SPECT/CT; MIRD method; exposure dose; thermoluminescent dosimeter (TLD); Alderson RANDO anthropomorphic phantom

J Nucl Med Technol 2010; 38:138-148

DOI: $10.2967 /$ jnmt.110.075770

$\mathbf{R}$ ecently, with the introduction of hybrid imaging devices such as PET/CT and SPECT/CT modalities, many reports describing the principles of the CT device $(1,2)$, and some clinical studies (3-12), have been published. Furthermore, there are also reports on the radiation exposure to radiologists $(13-17)$ in the operation of such devices and the measurement techniques of radiation exposure (18). However, none of these reports addressed in detail the radiation exposure to the patients.

In the operation of hybrid imaging modalities in the field of nuclear medicine, in addition to internal radiation exposure $(\gamma$-ray) resulting from the administration of radiopharmaceuticals, external radiation exposure (x-ray) from a CT device has to be taken into consideration in the light of recommendations from the International Commission on Radiological Protection (ICRP) (19-20). These recommendations include justification of practices (the use of radiation produces sufficient benefit to offset any risks caused by the use of radiation), optimization (the incurred exposure by the use of radiation should be kept as low as reasonably achievable), and dose limitation. The internal radiation exposure doses of each organ after radiopharmaceutical administration are calculated by the MIRD method (21). On the other hand, for the external radiation exposure dose 


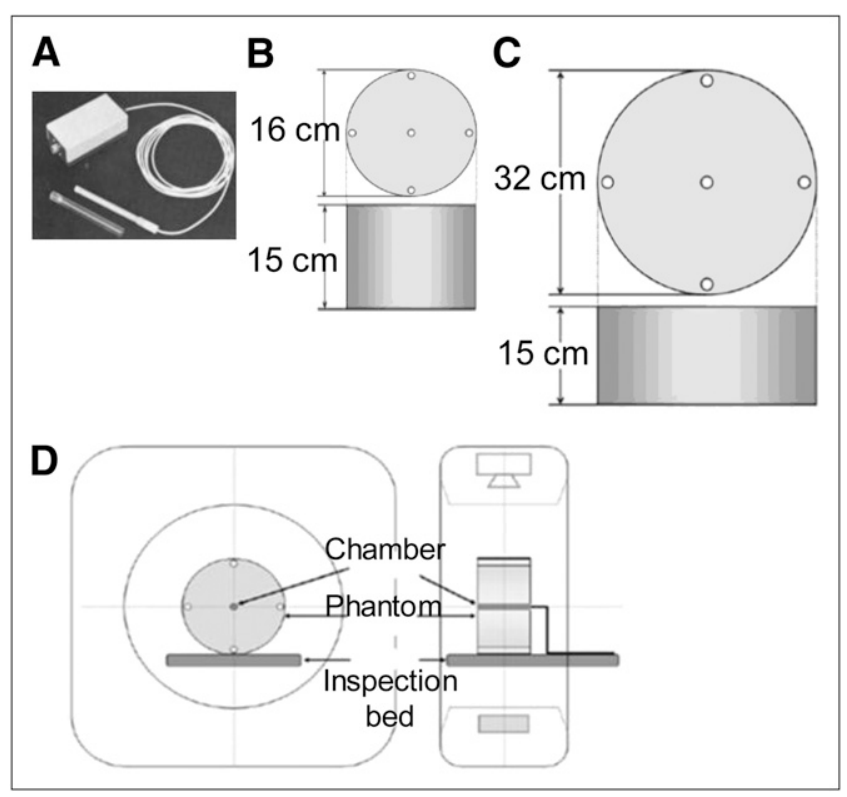

FIGURE 1. (A) Pencil-shaped ionization chamber dosimeter. (B) PMMA cylindric head phantom. (C) PMMA cylindric abdominal phantom. (D) Layout of measurement system setup.

from a CT device, CT dose index volume (CTDIvol), which is calculated from the CT conditions, is used as a reference value $(18,22)$ for CT radiation exposure. This is a calculated value unique to each device, not the value of external radiation exposures of each organ. Therefore, we believe that it is necessary to measure the detailed radiation exposure from CT. In the present study, using an Alderson RANDO anthropomorphic phantom (RAN-100; Phantom Laboratories), we estimated absorbed doses of x-rays of each organ under various CT conditions.

\section{MATERIALS AND METHODS}

\section{Measurement of CTDlvol Using CT Phantom}

A 16-slice CT device loaded in a Precedence SPECT/CT system (Philips) was used. In addition, the following devices were used: a radiation monitor (model 9015, 10x5-3CT; Radcal) (Fig. 1A) for measurements, polymethylmethacrylate (PMMA) cylindric head phantom $(15 \times 16$ $\mathrm{cm}$; Fig. 1B) as a pencil-shaped ionization chamber dosimeter, PMMA cylindric abdominal phantom $(15 \times 32 \mathrm{~cm}$; Fig. 1C), and Baromex (Sato Keiryoki MFG) system as a hygrometer/thermometer. The ionization chamber dosimeter and hygrometer/thermometer were calibrated according to the method of the Japan Quality Assurance Organization.

Figure 1D shows the layout of the measurement system setup. For the CT conditions, tube voltages of 90,120 , and $140 \mathrm{kVp}$ were used, and tube current-times of $25,50,100$, $150,200,250$, and $300 \mathrm{mAs}$ were applied at each tube voltage to obtain a CTDIvol for each imaging condition. We measured the CTDIvol of a CT device in accordance with the method of Goldman (18). The CTDIvols (index values) obtained from the scan device were compared and analyzed with the actual measured values.

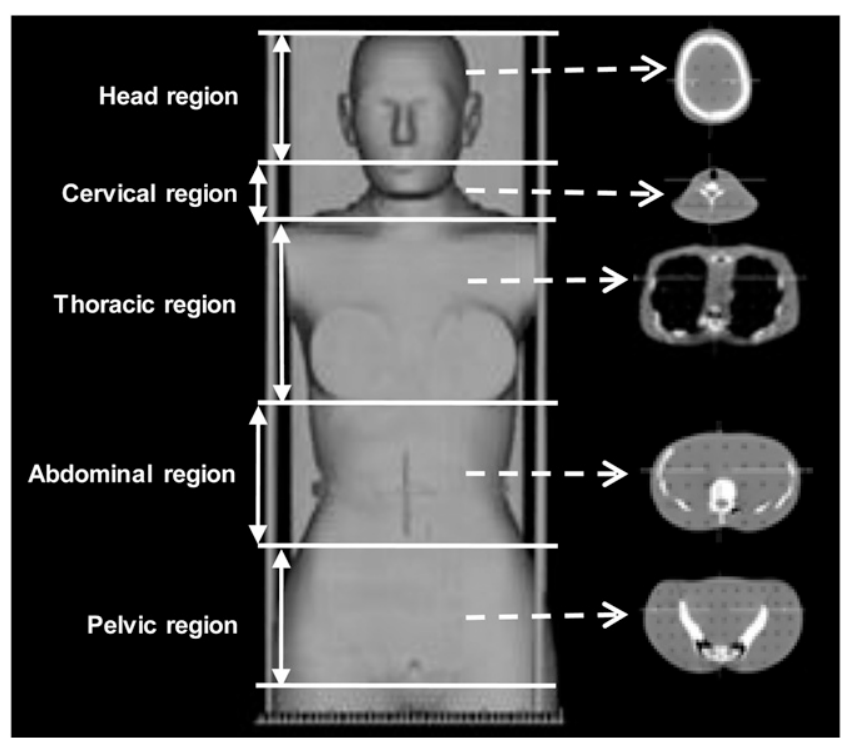

FIGURE 2. Alderson RANDO anthropomorphic phantom for deep-body total absorbed dose measurement.

\section{Absorbed Doses of Each Organ Using Anthropomorphic Phantom}

The Precedence SPECT/CT system (Philips) was used. In addition, we used a TLD reader (UD-512P; Panasonic) and TLD heat-treatment furnace (UD-606P; Panasonic) as measurement devices, a model UD-170L TLD (Panasonic), and a Baromex hygrometer/thermometer. The pencilshaped ionization chamber dosimeter and hygrometer/ thermometer was calibrated according to the method of the Japan Quality Assurance Organization.

The same tube voltages and currents as were used for CTDIvol were used to obtain radiation exposure doses by inserting 30 units of TLDs each at the head and cervical, thoracic, abdominal, and pelvic regions of the phantom (Fig. 2) under each imaging condition.

\section{TLD Protocol}

The specifications for the TLDs were as follows: model, UD-170L; luminescent material, beryllium oxide element; size, $1.2 \mathrm{~mm}$; diameter, $8 \mathrm{~mm}$; measuring range, $200 \mu \mathrm{Sv}$ to $20 \mathrm{~Sv}$; and measuring radiation type, $\mathrm{x}$-ray and $\gamma$-ray. After exposure to $400^{\circ} \mathrm{C}$ for $1 \mathrm{~h}$ and at $100^{\circ} \mathrm{C}$ for $6 \mathrm{~h}$ in an annealing oven (TLD heat-treatment furnace), TLDs were used for the CT scan and the data were collected using a TLD reader.

An organ-absorbed dose was calculated by multiplying the mean of the TLD readouts by a correction coefficient and a tissue dose-conversion coefficient (23) for each organ against air at the effective energy of the tube voltage applied. The radiation exposure dose (organ-absorbed dose) was derived from the absorbed dose of each organ (19). In addition, before the study, correction coefficients were obtained by comparing the measured values for each effective energy calculated with a CT device using an ionization chamber dosimeter (model 9015; Radcal) with the TLD measured values. 
FIGURE 3. CTDIvol measurement results of PMMA cylindric head phantom (A) and cylindric abdominal phantom (B) at each tube voltage and current. Actual $\mathrm{V}=$ actual measured values; Index $\mathrm{V}=$ index values.
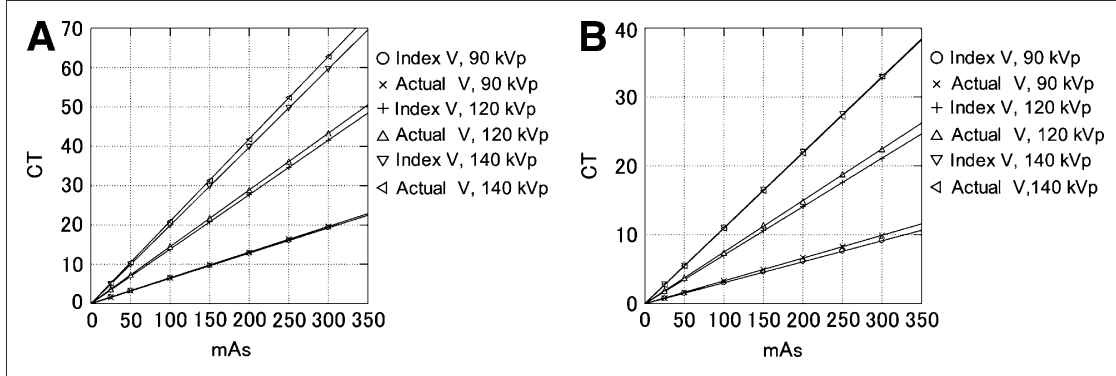

\section{RESULTS}

\section{Comparison of Measured Values and Index Values of CTDIvols}

Figures $3 \mathrm{~A}$ and $3 \mathrm{~B}$ show the actual measured and index values. In the PMMA cylindric head phantom, there was not much difference at $90 \mathrm{kVp}$. At 120 and $140 \mathrm{kVp}$, the index values were lower than the actual measured values as the current increased. In the PMMA cylindric abdominal phantom, the index values were lower than the actual measured values as the current increased at 90 and $120 \mathrm{kVp}$, but there was not much difference at $140 \mathrm{kVp}$.

\section{Absorbed Doses of Each Organ Using Anthropomorphic Phantom}

Figure 4 shows the measured and index values of the brain, eyes, thyroid glands, and lungs. Scans of the brain and eyes in the head region were acquired under the same conditions. The measured values of the brain gradually deviated from the corresponding index values as the current increased, whereas no deviations from the index values were observed for the measured values of the eyes as the current increased. Although the scans were obtained under the same condition, the values did not show a similar trend. In the cervical region (thyroid glands), the scans were acquired in such a way as to include the thoracic region. Accordingly, the CTDIvols of the cervical region were similar to those of the thoracic region.

Figure 5 shows the measured and index values of the mediastinum, skin of the thoracic region, liver, and kidneys. Although the scans were acquired under the same conditions on the skin surfaces of the thoracic (Fig. 5B) and pelvic (Fig. 6C) regions, there were differences in the TLD values between them.

Figure 6 shows the measured and index values of the urinary bladder, muscles, and skin of the pelvic region.

Figure 7 shows the measured and index values of the small intestine, large intestine, bones (red bone marrow), and ovaries.

Tables 1-3 show calculated TLD value-to-CTDIvol ratios. In the head region, the TLD values of were lower than the CTDIvols (TLD value-to-CTDIvol ratio, $0.93 \pm$ 0.12), whereas in the cervical, thoracic, abdominal, and pelvic regions, the TLD values were higher than the CTDIvols (TLD value-to-CTDIvol ratio, $1.78 \pm 0.41$ ) under each CT condition.
FIGURE 4. TLD measurement results of each organ in anthropomorphic phantom: head region, brain $(A)$; head region, eyes (B); cervical region, thyroid glands (C); thoracic region, lungs (D). Bra = Brain; Thy $=$ Thyroid glands.
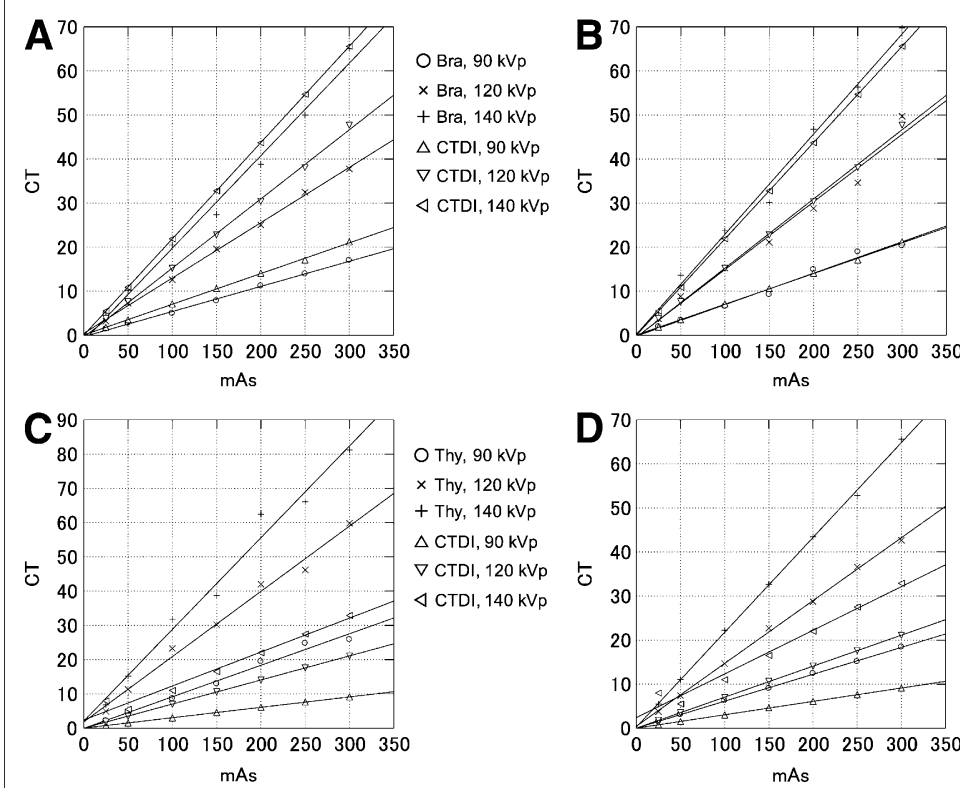

O Eye, $90 \mathrm{kVp}$ $\times$ Eye, $120 \mathrm{kVp}$ + Eye, $140 \mathrm{kVp}$ $\triangle \mathrm{CTDI}, 90 \mathrm{kVp}$ $\nabla \mathrm{CTDI}, 120 \mathrm{kVp}$ $\triangleleft \mathrm{CTDI}, 140 \mathrm{kVp}$

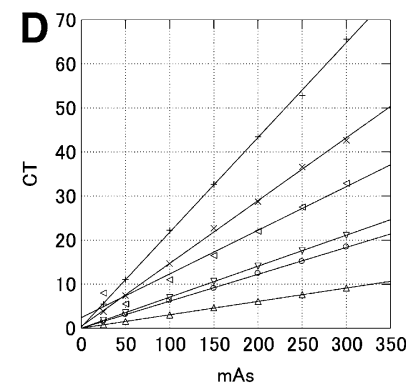

O Lung, $90 \mathrm{kVp}$ $\times$ Lung, $120 \mathrm{kVp}$ + Lung, $140 \mathrm{kVp}$ $\triangle \mathrm{CTDI}, 90 \mathrm{kVp}$ $\nabla \mathrm{CTDI}, 120 \mathrm{kVp}$ $\triangleleft \mathrm{CTDI}, 140 \mathrm{kVp}$ 


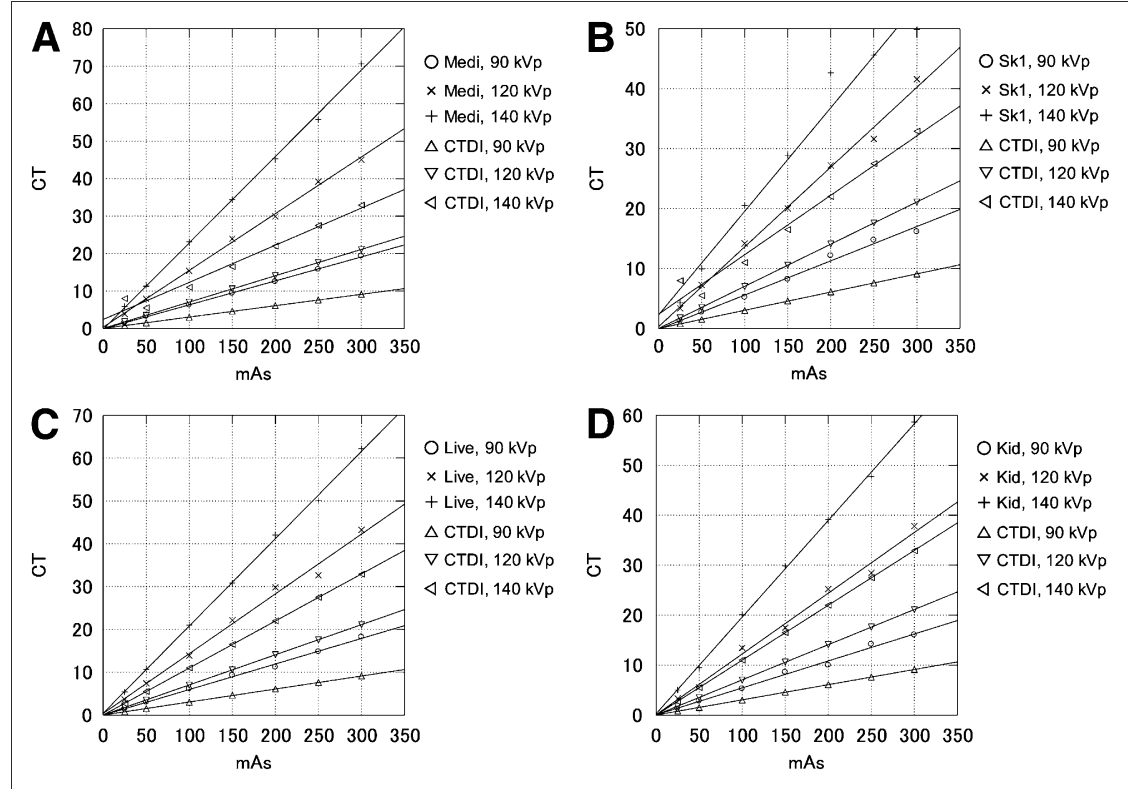

FIGURE 5. TLD measurement results of each organ in anthropomorphic phantom: thoracic region, mediastinum $(\mathrm{A})$; thoracic region, skin $(\mathrm{B})$; abdominal region, liver (C); abdominal region, kidneys (D). Medi = mediastinum; Kid = kidneys; Live = Liver; Sk1 $=$ skin of thoracic region.
Table 4 shows MIRD and TLD values of total (internal plus external) radiation exposure in the brain and liver, Appendices 1-5 show the radiation exposure doses by the MIRD method; Tables 1-3 also show radiation exposure doses measured using TLDs. These results suggest that detailed radiation exposure doses can be obtained by adding the MIRD and TLD values. In addition, we could obtain the detailed radiation exposure doses in a similar manner for other nuclear medicine modalities as well.

\section{DISCUSSION}

In the present study, we evaluated the radiation exposure doses from a CT device loaded in the hybrid imaging system. Although the imaging conditions in the study of Goldman (18) were $120 \mathrm{kVp}$ and $300 \mathrm{mAs}$ (number of settings, 1) for the PMMA cylindric head phantom and $120 \mathrm{kVp}$ and $250 \mathrm{mAs}$ (number of settings, 1) for the PMMA cylindric abdominal phantom, we used 21 different imaging condition settings with the PMMA cylindric head phantom and 21 different imaging condition settings with the PMMA cylindric abdominal phantom in the present study. Consequently, the index values of the CTDIvols were lower than the actual measured values under each imaging condition. It is likely that CTDIvol was underestimated because $\mathrm{x}$-rays with a wider beam width were used in multidetector CT and the formulas

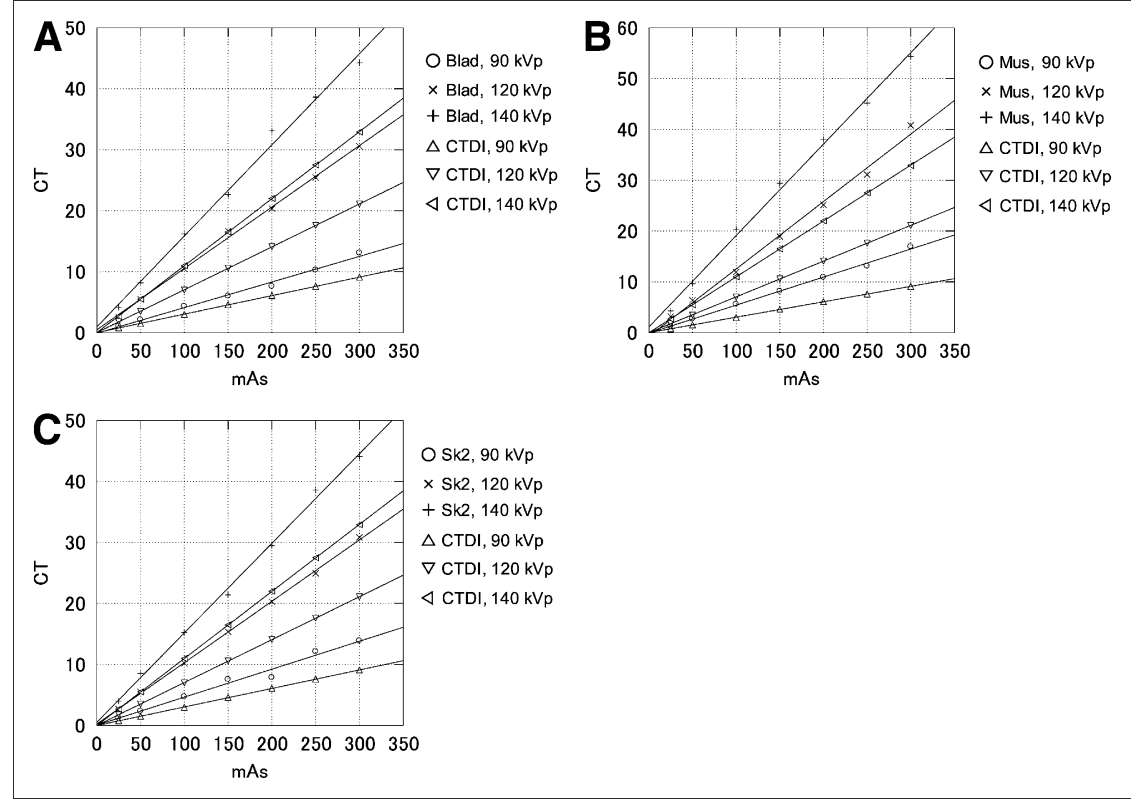

FIGURE 6. TLD measurement results of each organ in anthropomorphic phantom: pelvic region, urinary bladder $(A)$; pelvic region, muscles $(B)$; pelvic region, skin (C). Blad = urinary bladder; mus = muscles; Sk2 $=$ skin of pelvic region. 
FIGURE 7. TLD measurement results of each organ in anthropomorphic phantom: abdominal region, small intestine (A); abdominal region, large intestine $(B)$; abdominal region, bones (C); pelvic region, ovaries (D). Bon = bones; La_int = large intestine; Sm_int = small intestine; Ova = ovaries.

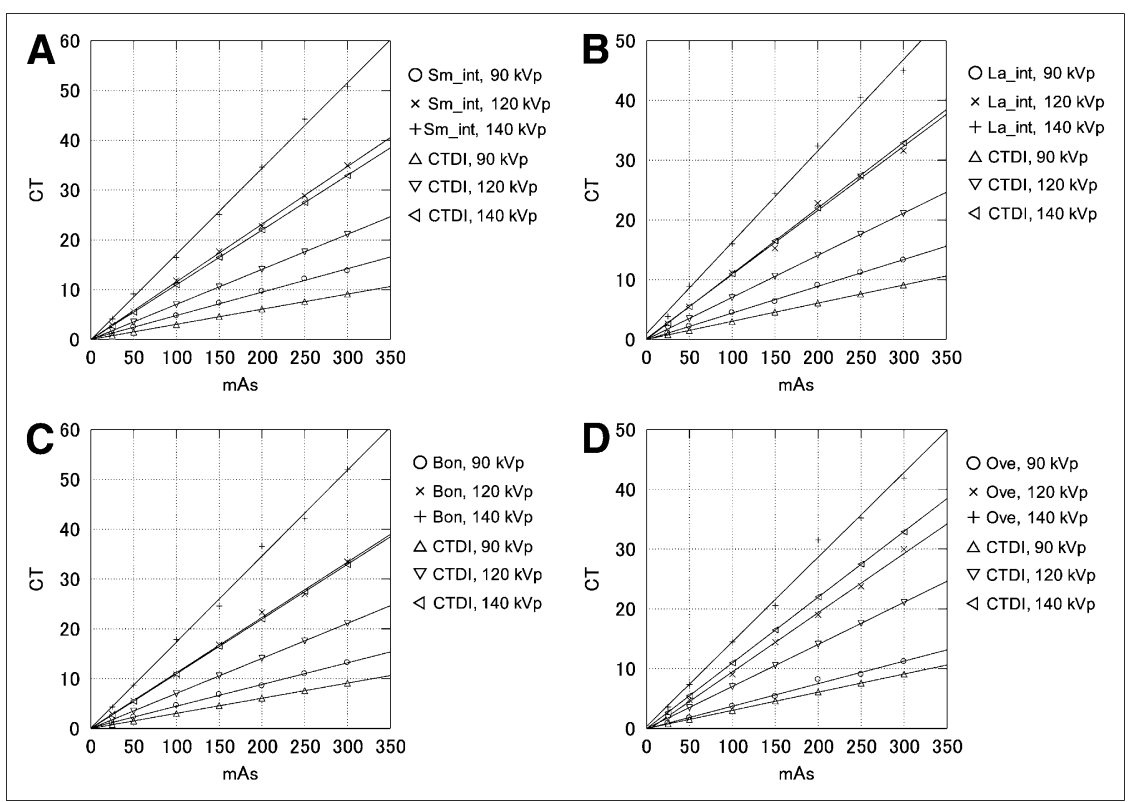

programmed in the system vary. Furthermore, the measurement method of radiation exposure doses described by Goldman (18) was for the device, not for human bodies. In the light of our present study, radiation exposure doses should be used as a reference only after the actual values of CTDIvol are measured and the specific features of each device are understood.

Guillet et al. (16) measured the radiation exposure of fingers from a PET device, Deloar et al. (17) measured the body surface radiation exposure using a MIRD phantom and TLDs from a PET device, and Lundberg et al. (13) measured the daily radiation exposure on the skin surface from a SPECT device (high-exposure modalities: gated heart-pool [900 MBq] and methoxyisobutylisonitrile stress [1,000 MBq] scans, 1.5-2 $\mu \mathrm{Sv} / \mathrm{h}$; low-exposure modalities: ${ }^{201} \mathrm{Tl}$ rest cardiac [40 MBq] and thyroid [150 MBq] scans, $0.2-0.4 \mu \mathrm{Sv} / \mathrm{h})$. However, these studies concerned occupational radiation exposures to the radiologists after administration of radiopharmaceuticals not radiation exposures to patients. Furthermore, there is currently no report on the radiation exposure from the $\mathrm{CT}$ component of the hybrid imaging system.

TABLE 1

Calculated TLD-to-CTDI ${ }_{\text {vol }}$ Ratios for Head Region

\begin{tabular}{|c|c|c|c|c|c|c|c|c|c|}
\hline \multirow[b]{2}{*}{ mAs } & \multicolumn{3}{|c|}{$90 \mathrm{kVp}$} & \multicolumn{3}{|c|}{$120 \mathrm{kVp}$} & \multicolumn{3}{|c|}{$140 \mathrm{kVp}$} \\
\hline & TDL & CTDI $I_{\mathrm{vol}}$ & Ratio & TDL & CTDI $_{\text {vol }}$ & Ratio & TDL & CTDI $_{\text {vol }}$ & Ratio \\
\hline \multicolumn{10}{|l|}{ Brain } \\
\hline 25 & 1.39 & 1.80 & 0.77 & 3.21 & 3.80 & 0.85 & 5.08 & 5.50 & 0.92 \\
\hline 50 & 2.76 & 3.50 & 0.79 & 7.29 & 7.60 & 0.96 & 10.18 & 10.90 & 0.93 \\
\hline 100 & 4.98 & 7.10 & 0.70 & 12.61 & 15.20 & 0.83 & 20.51 & 21.90 & 0.94 \\
\hline 150 & 7.82 & 10.60 & 0.74 & 19.60 & 22.80 & 0.86 & 27.37 & 32.80 & 0.83 \\
\hline 200 & 11.20 & 14.10 & 0.79 & 25.05 & 30.40 & 0.82 & 38.84 & 43.70 & 0.89 \\
\hline 250 & 13.93 & 17.10 & 0.81 & 32.48 & 38.10 & 0.85 & 49.98 & 54.70 & 0.91 \\
\hline 300 & 17.00 & 21.20 & 0.80 & 37.79 & 47.70 & 0.79 & 65.07 & 65.60 & 0.99 \\
\hline \multicolumn{10}{|l|}{ Eyes } \\
\hline 25 & 1.94 & 1.80 & 1.08 & 3.71 & 3.80 & 0.98 & 5.44 & 5.50 & 0.99 \\
\hline 50 & 3.44 & 3.50 & 0.98 & 8.82 & 7.60 & 1.16 & 13.66 & 10.90 & 1.25 \\
\hline 100 & 6.56 & 7.10 & 0.92 & 15.22 & 15.20 & 1.00 & 23.73 & 21.90 & 1.08 \\
\hline 150 & 9.27 & 10.60 & 0.87 & 21.11 & 22.80 & 0.93 & 30.14 & 32.80 & 0.92 \\
\hline 200 & 14.92 & 14.10 & 1.06 & 28.81 & 30.40 & 0.95 & 46.79 & 43.70 & 1.07 \\
\hline 250 & 18.93 & 17.10 & 1.11 & 34.61 & 38.10 & 0.91 & 56.30 & 54.70 & 1.03 \\
\hline 300 & 20.31 & 21.20 & 0.96 & 49.72 & 47.70 & 1.04 & 69.76 & 65.60 & 1.06 \\
\hline
\end{tabular}

Data are milligrays. 
TABLE 2

Calculated TLD-to-CTDI ${ }_{\text {vol }}$ Ratios for Cervical and Thoracic Regions

\begin{tabular}{|c|c|c|c|c|c|c|c|c|c|}
\hline \multirow[b]{2}{*}{ mAs } & \multicolumn{3}{|c|}{90 kVp } & \multicolumn{3}{|c|}{120 kVp } & \multicolumn{3}{|c|}{$140 \mathrm{kVp}$} \\
\hline & TDL & $\mathrm{CTDI}_{\mathrm{vol}}$ & Ratio & TDL & $\mathrm{CTDI}_{\mathrm{vol}}$ & Ratio & TDL & CTDI $_{\text {vol }}$ & Ratio \\
\hline \multicolumn{10}{|l|}{ Thyroid } \\
\hline 25 & 2.21 & 0.80 & 2.77 & 4.87 & 1.80 & 2.71 & 6.80 & 2.70 & 2.52 \\
\hline 50 & 4.70 & 1.50 & 3.13 & 11.34 & 3.50 & 3.24 & 15.18 & 5.50 & 2.76 \\
\hline 100 & 8.62 & 3.00 & 2.87 & 23.27 & 7.00 & 3.32 & 31.82 & 11.00 & 2.89 \\
\hline 150 & 12.97 & 4.60 & 2.82 & 30.18 & 10.60 & 2.85 & 38.70 & 16.50 & 2.35 \\
\hline 200 & 19.49 & 6.10 & 3.20 & 42.03 & 14.10 & 2.98 & 62.44 & 22.00 & 2.84 \\
\hline 250 & 24.76 & 7.60 & 3.26 & 46.17 & 17.60 & 2.62 & 66.12 & 27.50 & 2.40 \\
\hline 300 & 25.88 & 9.10 & 2.84 & 59.83 & 21.10 & 2.84 & 81.21 & 32.90 & 2.47 \\
\hline \multicolumn{10}{|l|}{ Lung } \\
\hline 25 & 1.51 & 0.80 & 1.89 & 3.76 & 1.80 & 2.09 & 5.45 & 2.70 & 2.02 \\
\hline 50 & 3.10 & 1.50 & 2.07 & 7.41 & 3.50 & 2.12 & 11.03 & 5.50 & 2.00 \\
\hline 100 & 6.25 & 3.00 & 2.08 & 14.66 & 7.00 & 2.09 & 22.21 & 11.00 & 2.02 \\
\hline 150 & 8.99 & 4.60 & 1.96 & 22.67 & 10.60 & 2.14 & 32.64 & 16.50 & 1.98 \\
\hline 200 & 12.42 & 6.10 & 2.04 & 28.72 & 14.10 & 2.04 & 43.49 & 22.00 & 1.98 \\
\hline 250 & 15.11 & 7.60 & 1.99 & 36.60 & 17.60 & 2.08 & 52.83 & 27.50 & 1.92 \\
\hline 300 & 18.42 & 9.10 & 2.02 & 42.65 & 21.10 & 2.02 & 65.61 & 32.90 & 1.99 \\
\hline \multicolumn{10}{|c|}{ Mediastinum } \\
\hline 25 & 1.54 & 0.80 & 1.93 & 3.87 & 1.80 & 2.15 & 5.90 & 2.70 & 2.19 \\
\hline 50 & 3.26 & 1.50 & 2.17 & 7.91 & 3.50 & 2.26 & 11.27 & 5.50 & 2.05 \\
\hline 100 & 6.29 & 3.00 & 2.10 & 15.37 & 7.00 & 2.20 & 23.16 & 11.00 & 2.11 \\
\hline 150 & 9.39 & 4.60 & 2.04 & 23.95 & 10.60 & 2.26 & 34.36 & 16.50 & 2.08 \\
\hline 200 & 12.51 & 6.10 & 2.05 & 29.92 & 14.10 & 2.12 & 45.27 & 22.00 & 2.06 \\
\hline 250 & 15.80 & 7.60 & 2.08 & 39.20 & 17.60 & 2.23 & 55.79 & 27.50 & 2.03 \\
\hline 300 & 19.34 & 9.10 & 2.13 & 45.05 & 21.10 & 2.13 & 70.64 & 32.90 & 2.15 \\
\hline \multicolumn{10}{|c|}{ Thoracic skin } \\
\hline 25 & 1.28 & 0.80 & 1.60 & 3.37 & 1.80 & 1.87 & 4.29 & 2.70 & 1.59 \\
\hline 50 & 2.71 & 1.50 & 1.81 & 7.24 & 3.50 & 2.07 & 9.94 & 5.50 & 1.81 \\
\hline 100 & 5.21 & 3.00 & 1.74 & 14.19 & 7.00 & 2.03 & 20.52 & 11.00 & 1.87 \\
\hline 150 & 8.21 & 4.60 & 1.78 & 20.04 & 10.60 & 1.89 & 28.91 & 16.50 & 1.75 \\
\hline 200 & 12.15 & 6.10 & 1.99 & 27.21 & 14.10 & 1.93 & 42.64 & 22.00 & 1.94 \\
\hline 250 & 14.76 & 7.60 & 1.94 & 31.62 & 17.60 & 1.80 & 45.60 & 27.50 & 1.66 \\
\hline 300 & 16.15 & 9.10 & 1.78 & 41.59 & 21.10 & 1.97 & 49.84 & 32.90 & 1.52 \\
\hline
\end{tabular}

Data are milligrays.

In the field of nuclear medicine, the internal radiation exposure doses of each organ after radiopharmaceutical administration are calculated by the MIRD method. For example, an internal radiation exposure index for brain perfusion scintigraphy is $0.8 \mathrm{mGy} / 37 \mathrm{MBq}$ for $N$-isopropyl-4-iodoamphetamine $\left({ }^{123} \mathrm{I}\right)$ hydrochloride or 0.19 $\mathrm{mGy} / 37 \mathrm{MBq}$ for ethyl cysteinate dimer (Appendices 1-5). On the other hand, regarding the external radiation exposure from a CT device, CTDIvol, dose-length product (24), and multiple-scan average dose-which is obtained from the CT condition-are generally used as reference values for $\mathrm{CT}$ radiation exposure. These are calculated values unique to each device and cannot be considered as an external radiation exposure of each organ. However, CTDIvol can be used as a reference of radiation exposure dose of the subject and is quite useful in managing the radiation exposure level. Actually, the International Atomic Energy Agency (IAEA) and ICRP adopt CTDI or multiple-scan average dose values as reference values of radiation exposure for the head $\mathrm{CT}$ and use them in their reports (IAEA, $50 \mathrm{mGy}$ [multiple-scan average dose]; ICRP, $60 \mathrm{mGy}$ [CTDI $_{100}$; the International Electrotechnical Commission definition of CT dose]; and Japan Association of Radiological Technologists, $65 \mathrm{mGy}$ [CTDIvol]). According to the results of our present study, the imaging conditions matching the radiation exposure reported by the IAEA, ICRP, and Japan Association of Radiological Technologists are higher than $300 \mathrm{mAs}$ at $120 \mathrm{kVp}$ and correspond to $250-300 \mathrm{mAs}$ at $140 \mathrm{kVp}$. The imaging condition of the head (in adults) in the actual clinical settings is $120 \mathrm{kVp}$ (tube voltage) and $200-300$ $\mathrm{mAs}$, and under this imaging condition, the radiation exposure dose and CTDIvol are 28.81-49.72 mGy and 30.4-47.7 mGy, respectively. It has been recognized that the reference values of each tissue tend to be overestimated, as compared with their corresponding radiation exposure doses (Tables 1-3). In addition, CTDIvols were underestimated, except for those in the brain region. Our results clarified that the radiation exposure dose of TLDs calculated using a phantom for deep-body total dose 
TABLE 3

Calculated TLD-to-CTDI ${ }_{\text {vol }}$ Ratios for Abdominal and Pelvic Regions

\begin{tabular}{|c|c|c|c|c|c|c|c|c|c|}
\hline \multirow[b]{2}{*}{$\mathrm{mAs}$} & \multicolumn{3}{|c|}{$90 \mathrm{kVp}$} & \multicolumn{3}{|c|}{$120 \mathrm{kVp}$} & \multicolumn{3}{|c|}{$140 \mathrm{kVp}$} \\
\hline & TDL & CTDI $_{\text {vol }}$ & Ratio & TDL & $\mathrm{CTDI}_{\mathrm{vol}}$ & Ratio & TDL & $\mathrm{CTDI}_{\mathrm{vol}}$ & Ratio \\
\hline \multicolumn{10}{|l|}{ Liver } \\
\hline 25 & 1.40 & 0.80 & 1.76 & 3.64 & 1.80 & 2.02 & 5.37 & 2.70 & 1.99 \\
\hline 50 & 2.99 & 1.50 & 1.99 & 7.41 & 3.50 & 2.12 & 10.69 & 5.50 & 1.94 \\
\hline 100 & 6.16 & 3.00 & 2.05 & 13.88 & 7.00 & 1.98 & 21.01 & 11.00 & 1.91 \\
\hline 150 & 9.29 & 4.60 & 2.02 & 22.13 & 10.60 & 2.09 & 30.82 & 16.50 & 1.87 \\
\hline 200 & 11.19 & 6.10 & 1.83 & 29.81 & 14.10 & 2.11 & 42.04 & 22.00 & 1.91 \\
\hline 250 & 14.80 & 7.60 & 1.95 & 32.64 & 17.60 & 1.85 & 50.08 & 27.50 & 1.82 \\
\hline 300 & 18.23 & 9.10 & 2.00 & 43.23 & 21.10 & 2.05 & 62.19 & 32.90 & 1.89 \\
\hline Kidney & 1.36 & 0.80 & 1.69 & 3.31 & 1.80 & 1.84 & 5.03 & 2.70 & 1.86 \\
\hline 25 & 2.81 & 1.50 & 1.88 & 5.55 & 3.50 & 1.59 & 9.46 & 5.50 & 1.72 \\
\hline 50 & 5.29 & 3.00 & 1.76 & 13.45 & 7.00 & 1.92 & 20.08 & 11.00 & 1.83 \\
\hline 100 & 8.59 & 4.60 & 1.87 & 17.46 & 10.60 & 1.65 & 29.86 & 16.50 & 1.81 \\
\hline 150 & 9.99 & 6.10 & 1.64 & 25.21 & 14.10 & 1.79 & 39.07 & 22.00 & 1.78 \\
\hline 200 & 14.18 & 7.60 & 1.87 & 28.42 & 17.60 & 1.61 & 47.71 & 27.50 & 1.73 \\
\hline 250 & 16.05 & 9.10 & 1.76 & 37.81 & 21.10 & 1.79 & 58.64 & 32.90 & 1.78 \\
\hline 300 & 1.36 & 0.80 & 1.69 & 3.31 & 1.80 & 1.84 & 5.03 & 2.70 & 1.86 \\
\hline \multicolumn{10}{|c|}{ Small intestine } \\
\hline 25 & 1.14 & 0.80 & 1.43 & 2.92 & 1.80 & 1.62 & 4.16 & 2.70 & 1.54 \\
\hline 50 & 2.46 & 1.50 & 1.64 & 5.60 & 3.50 & 1.60 & 9.15 & 5.50 & 1.66 \\
\hline 100 & 4.78 & 3.00 & 1.59 & 11.84 & 7.00 & 1.69 & 16.49 & 11.00 & 1.50 \\
\hline 150 & 7.29 & 4.60 & 1.58 & 17.65 & 10.60 & 1.67 & 25.08 & 16.50 & 1.52 \\
\hline 200 & 9.69 & 6.10 & 1.59 & 22.72 & 14.10 & 1.61 & 34.58 & 22.00 & 1.57 \\
\hline 250 & 12.18 & 7.60 & 1.60 & 28.82 & 17.60 & 1.64 & 44.23 & 27.50 & 1.61 \\
\hline 300 & 13.81 & 9.10 & 1.52 & 34.94 & 21.10 & 1.66 & 50.75 & 32.90 & 1.54 \\
\hline \multicolumn{10}{|c|}{ Large intestine } \\
\hline 25 & 1.06 & 0.80 & 1.32 & 2.64 & 1.80 & 1.47 & 3.85 & 2.70 & 1.43 \\
\hline 50 & 2.21 & 1.50 & 1.47 & 5.50 & 3.50 & 1.57 & 8.93 & 5.50 & 1.62 \\
\hline 100 & 4.50 & 3.00 & 1.50 & 11.15 & 7.00 & 1.59 & 16.02 & 11.00 & 1.46 \\
\hline 150 & 6.33 & 4.60 & 1.38 & 15.27 & 10.60 & 1.44 & 24.41 & 16.50 & 1.48 \\
\hline 200 & 9.08 & 6.10 & 1.49 & 22.81 & 14.10 & 1.62 & 32.36 & 22.00 & 1.47 \\
\hline 250 & 11.21 & 7.60 & 1.48 & 27.27 & 17.60 & 1.55 & 40.52 & 27.50 & 1.47 \\
\hline 300 & 13.29 & 9.10 & 1.46 & 31.59 & 21.10 & 1.50 & 45.02 & 32.90 & 1.37 \\
\hline \multicolumn{10}{|l|}{ Ovary } \\
\hline 25 & 0.90 & 0.80 & 1.13 & 2.30 & 1.80 & 1.28 & 3.59 & 2.70 & 1.33 \\
\hline 50 & 1.79 & 1.50 & 1.19 & 4.82 & 3.50 & 1.38 & 7.37 & 5.50 & 1.34 \\
\hline 100 & 3.72 & 3.00 & 1.24 & 9.09 & 7.00 & 1.30 & 14.52 & 11.00 & 1.32 \\
\hline 150 & 5.38 & 4.60 & 1.17 & 14.44 & 10.60 & 1.36 & 20.57 & 16.50 & 1.25 \\
\hline 200 & 8.20 & 6.10 & 1.34 & 19.01 & 14.10 & 1.35 & 31.54 & 22.00 & 1.43 \\
\hline 250 & 9.06 & 7.60 & 1.19 & 23.80 & 17.60 & 1.35 & 35.23 & 27.50 & 1.28 \\
\hline 300 & 11.22 & 9.10 & 1.23 & 29.99 & 21.10 & 1.42 & 41.90 & 32.90 & 1.27 \\
\hline \multicolumn{10}{|c|}{ Urinary bladder } \\
\hline 25 & 1.07 & 0.80 & 1.34 & 2.56 & 1.80 & 1.42 & 4.11 & 2.70 & 1.52 \\
\hline 50 & 2.13 & 1.50 & 1.42 & 5.52 & 3.50 & 1.58 & 8.17 & 5.50 & 1.49 \\
\hline 100 & 4.35 & 3.00 & 1.45 & 10.47 & 7.00 & 1.50 & 16.21 & 11.00 & 1.47 \\
\hline 150 & 6.01 & 4.60 & 1.31 & 16.68 & 10.60 & 1.57 & 22.66 & 16.50 & 1.37 \\
\hline 200 & 7.61 & 6.10 & 1.25 & 20.34 & 14.10 & 1.44 & 33.14 & 22.00 & 1.51 \\
\hline 250 & 10.29 & 7.60 & 1.35 & 25.41 & 17.60 & 1.44 & 38.64 & 27.50 & 1.41 \\
\hline 300 & 13.09 & 9.10 & 1.44 & 30.55 & 21.10 & 1.45 & 44.23 & 32.90 & 1.34 \\
\hline \multicolumn{10}{|c|}{ Red bone marrow } \\
\hline 25 & 1.11 & 0.80 & 1.38 & 2.92 & 1.80 & 1.62 & 4.33 & 2.70 & 1.60 \\
\hline 50 & 2.29 & 1.50 & 1.53 & 5.55 & 3.50 & 1.59 & 8.72 & 5.50 & 1.58 \\
\hline 100 & 4.65 & 3.00 & 1.55 & 10.83 & 7.00 & 1.55 & 17.88 & 11.00 & 1.63 \\
\hline 150 & 6.84 & 4.60 & 1.49 & 16.83 & 10.60 & 1.59 & 24.55 & 16.50 & 1.49 \\
\hline 200 & 8.59 & 6.10 & 1.41 & 23.32 & 14.10 & 1.65 & 36.56 & 22.00 & 1.66 \\
\hline 250 & 11.02 & 7.60 & 1.45 & 26.99 & 17.60 & 1.53 & 42.14 & 27.50 & 1.53 \\
\hline 300 & 13.24 & 9.10 & 1.45 & 33.50 & 21.10 & 1.59 & 52.07 & 32.90 & 1.58 \\
\hline \multicolumn{10}{|l|}{ Muscle } \\
\hline 25 & 1.28 & 0.80 & 1.60 & 3.19 & 1.80 & 1.77 & 4.29 & 2.70 & 1.59 \\
\hline 50 & 2.68 & 1.50 & 1.79 & 6.39 & 3.50 & 1.83 & 9.64 & 5.50 & 1.75 \\
\hline
\end{tabular}

144 Journal of Nuclear Medicine Technology • Vol. 38 • No. 3 • September 2010 
TABLE 3

(Continued)

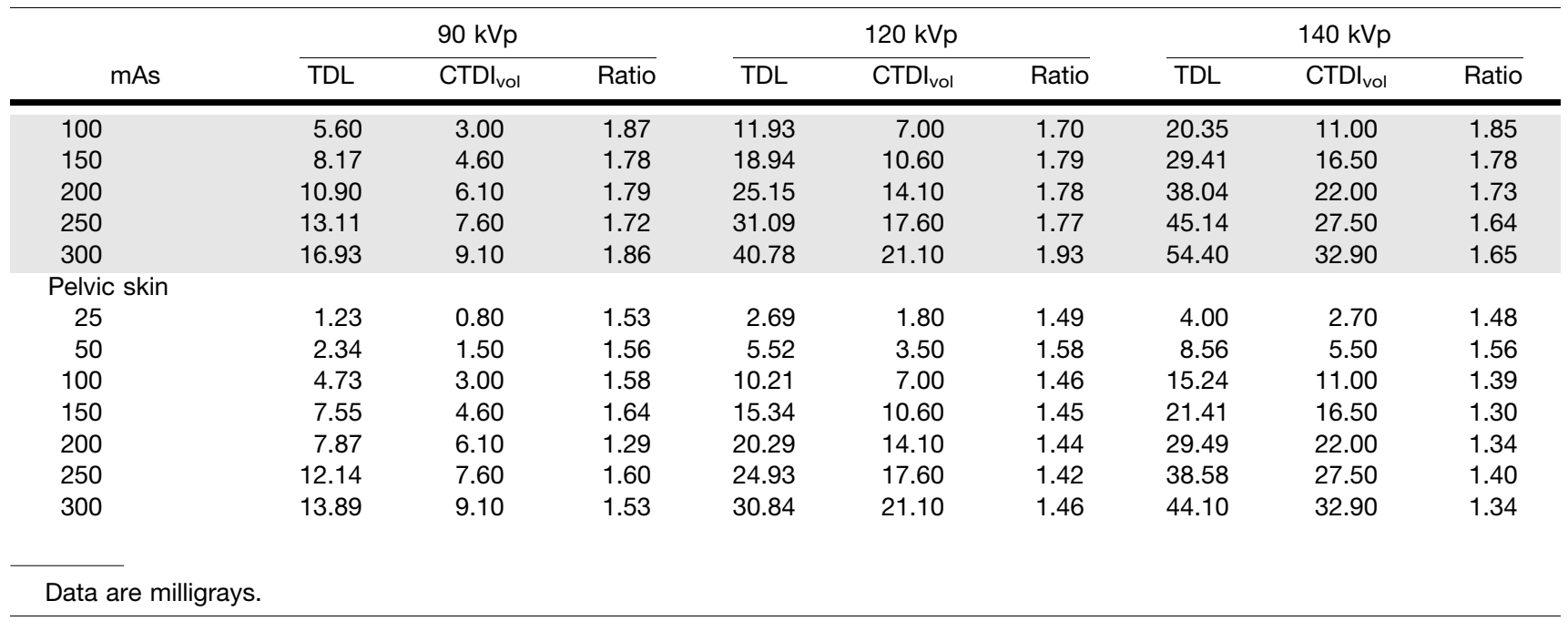

measurement should be used as a reference value of radiation exposure in the patients (Tables 1-3).

ICRP (25) recommends maintaining the appropriate balance between the medical benefits and risks of potentially inducing cancer in patients at a dose level produced by a CT examination. Considering this recommendation, CTDI- vol is not sufficient to understand the absorbed dose of a specific organ, and it is thus difficult to take appropriate precautions against the risks of inducing cancer. Therefore, it is necessary to assess the absorbed dose at the organ level. In the present study, we assessed the absorbed doses at an organ level by changing the tube voltages and currents. To

TABLE 4

MIRD and TLD Values of Total Radiation Exposure in Brain and Liver

\begin{tabular}{|c|c|c|c|c|c|c|}
\hline \multirow[b]{2}{*}{$\begin{array}{l}\text { Imaging } \\
\text { condition }\end{array}$} & \multicolumn{3}{|c|}{ Head region } & \multicolumn{3}{|c|}{ Abdominal region } \\
\hline & $\begin{array}{l}\text { Brain perfusion scintigraphy } \\
\text { ( } N \text {-isopropyl- } \\
\text { 4-iodoamphetamine }\left({ }^{123} \mathrm{l}\right) \\
\text { hydrochloride, } 111 \mathrm{MBq})\end{array}$ & $\begin{array}{c}\mathrm{CT} \\
\text { (brain) }\end{array}$ & $\begin{array}{l}\text { Total radiation } \\
\text { exposure (mGy) }\end{array}$ & $\begin{array}{l}\text { Liver scintigraphy } \\
\text { (galactosyl human serum } \\
\text { albumin diethylenetriamine } \\
\text { pentaacetic acid, } 185 \mathrm{MBq} \text { ) }\end{array}$ & $\begin{array}{l}\text { CT } \\
\text { (liver) }\end{array}$ & $\begin{array}{l}\text { Total radiation } \\
\text { exposure (mGy) }\end{array}$ \\
\hline \multicolumn{7}{|l|}{90 kVp } \\
\hline 25 mAs & 2.52 & +1.39 & 3.91 & 9.99 & +1.40 & 11.39 \\
\hline $50 \mathrm{mAs}$ & & +2.76 & 5.28 & & +2.99 & 12.98 \\
\hline $100 \mathrm{mAs}$ & & +4.98 & 7.50 & & +6.16 & 16.15 \\
\hline $150 \mathrm{mAs}$ & & +7.82 & 10.34 & & +9.29 & 19.28 \\
\hline $200 \mathrm{mAs}$ & & +11.20 & 13.72 & & +11.19 & 21.18 \\
\hline $250 \mathrm{mAs}$ & & +13.93 & 16.45 & & +14.80 & 24.79 \\
\hline $300 \mathrm{mAs}$ & & +17.00 & 19.52 & & +18.23 & 28.22 \\
\hline \multicolumn{7}{|l|}{$120 \mathrm{kVp}$} \\
\hline 25 mAs & 2.52 & +3.21 & 5.73 & 9.99 & +3.64 & 13.63 \\
\hline $50 \mathrm{mAs}$ & & +7.29 & 9.81 & & +7.41 & 17.40 \\
\hline $100 \mathrm{mAs}$ & & +12.61 & 15.13 & & +13.88 & 23.87 \\
\hline $150 \mathrm{mAs}$ & & +19.60 & 22.12 & & +22.13 & 32.12 \\
\hline $200 \mathrm{mAs}$ & & +25.05 & 27.57 & & +29.81 & 39.80 \\
\hline $250 \mathrm{mAs}$ & & +32.48 & 35.00 & & +32.64 & 42.63 \\
\hline $300 \mathrm{mAs}$ & & +37.79 & 40.31 & & +43.23 & 53.22 \\
\hline \multicolumn{7}{|l|}{140 kVp } \\
\hline $25 \mathrm{mAs}$ & 2.52 & +5.08 & 7.60 & 9.99 & +5.37 & 20.68 \\
\hline $50 \mathrm{mAs}$ & & +10.18 & 12.70 & & +10.69 & 20.68 \\
\hline $100 \mathrm{mAs}$ & & +20.51 & 23.03 & & +21.01 & 31.00 \\
\hline $150 \mathrm{mAs}$ & & +27.37 & 29.89 & & +30.82 & 40.81 \\
\hline $200 \mathrm{mAs}$ & & +38.83 & 41.35 & & +42.04 & 52.03 \\
\hline $250 \mathrm{mAs}$ & & +49.98 & 52.50 & & +50.08 & 60.07 \\
\hline $300 \mathrm{mAs}$ & & +65.07 & 67.59 & & +62.19 & 72.18 \\
\hline
\end{tabular}


obtain radiation dose estimates without restriction to specific CT devices from various manufacturers, we did not use the CT exposure-reducing technology (DoseRight automatic current selection, DoseRight dose modulation, DoseRight electrocardiogram-gated modulation, and such [all from Phillips]; Appendix 6) loaded in the CT device in our present study. With this employment, our present results can be used as references for the radiation exposure doses of each organ without restriction to a specific CT device manufacturer and can be applied to any CT device loaded in a PET/CT system as well.

\section{CONCLUSION}

Estimation of the external radiation exposures (x-ray) of each organ under a certain CT condition, along with internal radiation exposure ( $\gamma$-ray) resulting from the administration of radiopharmaceuticals, helps us understand the detailed radiation exposure from various nuclear medicine modalities (SPECT/CT) and seems to be useful as a reference value of radiation exposure for performing these examinations. In addition, this information is also useful for explaining the examinations to the patients.

\section{APPENDIX 1}

Exposure Doses in Head Region According to MIRD Method

\begin{tabular}{|c|c|c|c|c|}
\hline Organ & ${ }^{111}$ In-diethylenetriaminepentaacetic acid & $\begin{array}{c}N \text {-isopropyl-4- } \\
\text { iodoamphetamine }\left({ }^{123} \mid\right) \\
\text { hydrochloride }\end{array}$ & 123/-iomazenil & $\begin{array}{c}99 m \text { Tc-ethyl } \\
\text { cysteinate dimer }\end{array}$ \\
\hline Brain & 41 & 0.84 & 0.44 & 0.0051 \\
\hline Body & 1.5 & 0.38 & 0.17 & 0.001 \\
\hline
\end{tabular}

APPENDIX 2

Exposure Doses in Cervical Region According to MIRD Method

\begin{tabular}{lccc}
\hline Organ & $\begin{array}{c}123 \mathrm{I} \\
\text { capsule }\end{array}$ & $\begin{array}{c}131 \mathrm{I} \\
\text { capsule }\end{array}$ & 99mTcO4 $^{-}$ \\
\hline Thyroid & 13 & 1,300 & 0.11 \\
Body & 0.029 & 0.71 & 0.09
\end{tabular}

Organ-absorbed doses are given in mGy/37 MBq.

APPENDIX 3

Exposure Doses in Thoracic Region According to MIRD Method

\begin{tabular}{|c|c|c|c|c|c|c|c|}
\hline Organ & $\begin{array}{l}\text { 99mTc-human serum } \\
\text { albumin } \\
\text { diethylenetriamine } \\
\text { pentaacetic acid }\end{array}$ & $\begin{array}{l}99 \mathrm{mTc}- \\
\text { tetrofosmin } \\
\quad \text { (rest) }\end{array}$ & $\begin{array}{l}\text { 99mTc- } \\
\text { methoxyisobutylisonitrile } \\
\text { (rest) }\end{array}$ & ${ }^{201} \mathrm{TICl}$ & $\begin{array}{c}\text { 123l-15-(4-iodophenyl)- } \\
\text { 3(R,S)- } \\
\text { methylpentadecanoic } \\
\text { acid }\end{array}$ & $\begin{array}{l}99 \mathrm{~m} T \mathrm{c}- \\
\text { macroaggregated } \\
\text { albumin }\end{array}$ & $\begin{array}{c}81 \mathrm{mKr} \\
\text { gas }\end{array}$ \\
\hline Heart & 0.64 & 0.0041 & 0.34 & 6.4 & 0.057 & - & - \\
\hline Lung & 0.17 & 0.0023 & 0.045 & 2.4 & - & 3 & 17 \\
\hline Liver & 0.57 & 0.0032 & 0.14 & 4.7 & 0.038 & 0.43 & 0.27 \\
\hline Kidney & 0.48 & 0.0104 & 0.62 & 4.0 & 0.011 & 1.1 & 0.1 \\
\hline Body & 0.16 & 0.0038 & 0.089 & 1.7 & 0.01 & 0.19 & 0.04 \\
\hline
\end{tabular}

Organ-absorbed doses are given in $\mathrm{mGy} / 37 \mathrm{MBq}$ for ${ }^{99 \mathrm{mT}} \mathrm{Tc}-$ human serum albumin diethylenetriamine pentaacetic acid, $99 \mathrm{~m} \mathrm{Tc}-$

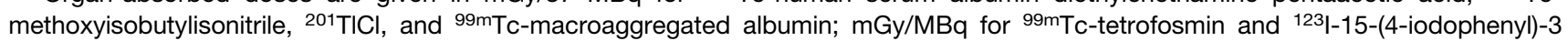
$(R, S)$-methylpentadecanoic acid; and $\mu \mathrm{Gy} / 37 \mathrm{MBq}$ for ${ }^{81 \mathrm{~m}} \mathrm{Kr}$ gas. 
APPENDIX 4

Exposure Doses in Abdominal Region According to MIRD Method

\begin{tabular}{|c|c|c|c|c|c|}
\hline Organ & $\begin{array}{c}99 \mathrm{~m} \text { Tc- } \\
\text { stannous colloid }\end{array}$ & $\begin{array}{l}\text { 99mTc-N-pyridoxyl- } \\
\text { 5-methyltryptophan }\end{array}$ & $\begin{array}{l}\text { 99mTc-galactosyl human } \\
\text { serum albumin } \\
\text { diethylenetriamine } \\
\text { pentaacetic acid }\end{array}$ & $\begin{array}{c}99 \mathrm{mTc}- \\
\text { mercaptoacetylglycylglycylglycin }\end{array}$ & $\begin{array}{c}131 \mid- \\
\text { adosterol }\end{array}$ \\
\hline Liver & 3.2 & 0.5 & 0.054 & 0.0006 & 8.0 \\
\hline Kidney & - & 0.2 & 0.0081 & 0.0028 & 4.6 \\
\hline Ovaries & 0.06 & 0.9 & - & - & 40.3 \\
\hline Body & 0.2 & 0.2 & 0.0011 & 0.001 & 4.4 \\
\hline
\end{tabular}

Organ-absorbed doses are given in mGy/37 MBq for ${ }^{99 m T c-s t a n n o u s ~ c o l l o i d ~ a n d ~}{ }^{99 m} \mathrm{Tc}-N$-pyridoxyl-5-methyltryptophan, mGy/MBq for 99mTc-galactosyl human serum albumin diethylenetriamine pentaacetic acid and ${ }^{99 m T c-m e r c a p t o a c e t y l g l y c y l g l y c y l g l y c i n, ~ a n d ~ m G y / 18.5 ~}$ MBq for ${ }^{131}$ I-adosterol.

APPENDIX 5

Exposure Doses in Total Body According to MIRD Method

\begin{tabular}{|c|c|c|c|c|c|}
\hline Organ & $\begin{array}{l}99 \mathrm{mTc}- \\
\text { hydroxymethylenediphosphonate }\end{array}$ & $\begin{array}{l}\text { 99mTc- } \\
\text { methylenediphosphonate }\end{array}$ & ${ }^{67} \mathrm{Ga}$-citrate & ${ }^{201} \mathrm{TICl}$ & ${ }^{18} \mathrm{~F}-\mathrm{FDG}$ \\
\hline Liver & 0.086 & 0.07 & 4.6 & 4.7 & 3.7 \\
\hline Kidney & 0.219 & 0.81 & 4.1 & 4 & 4.4 \\
\hline Ovaries & 0.1 & 0.09 & 2.8 & 7.1 & 1.9 \\
\hline Bone & 0.512 & 0.46 & 4.4 & - & - \\
\hline Bone marrow (red) & 0.331 & - & - & - & 1.7 \\
\hline Body & 0.119 & 0.07 & 2.6 & 1.7 & 1.9 \\
\hline
\end{tabular}

Organ-absorbed doses are given in mGy/37 MBq.

\section{APPENDIX 6}

Philips Dose-Management List

\begin{tabular}{ll}
\hline \multicolumn{1}{c}{ Feature } & \multicolumn{1}{c}{ Description } \\
\hline 1: IntelliBeam filtration & \\
2-1: DoseRight automatic current selection & Auto current selection (ACS) \\
2-2: DoseRight dose modulation & Dynamic dose modulation (D-DOM) \\
& Z-direction dose modulation (Z-DOM) \\
3-1: DoseRight cardiac & Cardiac dose modulation \\
3-2: DoseRight electrocardiogram-gated modulation & \\
\hline
\end{tabular}

\section{ACKNOWLEDGMENTS}

We thank Teruhiko Takayama, Kayo Hara, Kohana Hara, Konomi Hara, and all the radiologic technologists of Sumitomo Hospital for technical support.

\section{REFERENCES}

1. Goldman LW. Principles of CT: multislice CT. J Nucl Med Technol. 2008;36:57-68.

2. Goldman LW. Principles of CT and CT technology. J Nucl Med Technol. 2007;35:115-128.

3. Even-Sapir E, Flusser G, Lerman H, et al. SPECT/multislice low-dose CT: a clinically relevant constituent in the imaging algorithm of nononcologic patients referred for bone scintigraphy. J Nucl Med. 2007;48:319-324.

4. Leman H, Lievshitz G, Zak O, Metser U, Schneebaum S, Even-Sapir E. Improved sentinel node identification by SPECT/CT in overweight patients with breast cancer. J Nucl Med. 2007;48:201-206.
5. Belhocine TZ, Scott AM, Even-Sapir E, Urbain JL, Essner R. Role of nuclear medicine in the management of cutaneous malignant melanoma. J Nucl Med. 2006;47:957-967.

6. Even-Sapir E, Metser U, Mishani E, et al. The detection of bone metastases in patients with high-risk prostate cancer: ${ }^{99 \mathrm{~m}} \mathrm{Tc}-\mathrm{MDP}$ planar bone scintigraphy, single- and multi-field-of-view SPECT, ${ }^{18} \mathrm{~F}$-fluoride PET, and ${ }^{18} \mathrm{~F}$-fluoride PET/ CT. J Nucl Med. 2006;47:287-297.

7. Metser U, Miller E, Lerman H, et al. ${ }^{18} \mathrm{~F}-\mathrm{FDG}$ PET/CT in the evaluation of adrenal masses. J Nucl Med. 2006;47:32-37.

8. Even-Sapir E. Imaging of malignant bone involvement by morphologic, scintigraphic, and hybrid modalities. J Nucl Med. 2005;46:1356-1367.

9. Metser U, Miller E, Kessler A, et al. Solid splenic masses: evaluation with ${ }^{18} \mathrm{~F}-$ FDG PET/CT. J Nucl Med. 2005;46:52-59.

10. Lerman H, Metser U, Grisaru D, Fishman A, Lievshitz G, Even-Sapir E. Normal and abnormal ${ }^{18} \mathrm{~F}-\mathrm{FDG}$ endometrial and ovarian uptake in pre- and postmenopausal patients: assessment by PET/CT. J Nucl Med. 2004;45:266271.

11. Even-Sapir E, Metser U, Flusser G, et al. Assessment of malignant skeletal disease: initial experience with ${ }^{18} \mathrm{~F}$-fluoride PET/CT and comparison 
between ${ }^{18}$ F-fluoride PET and ${ }^{18}$ F-fluoride PET/CT. J Nucl Med. 2004;45: 272-278.

12. Metser U, Lerman H, Blank A, Lievshitz G, Bokstein F, Even-Sapir E. Malignant involvement of the spine: assessment by ${ }^{18}$ F-FDG PET/CT. J Nucl Med. 2004;45:279-284.

13. Lundberg TM, Gray PJ, Bartlett ML. Measuring and minimizing the radiation dose to nuclear medicine technologists. J Nucl Med Technol. 2002;30:25-30.

14. Chiesa C, De Sanctis V, Crippa F, et al. Radiation dose to technicians per nuclear medicine procedure: comparison between technetium-99m, gallium-67, and iodine-131 radiotracers and fluorine-18 fluodeoxyglucose. Eur J Nucl Med. 1997;24:1380-1389.

15. Roberts FO, Gunawardana DH, Pathmarai K, et al. Radiation dose to PET technologists and strategies to lower occupational exposure. J Nucl Med Technol. 2005;33:44-47.

16. Guillet B, Quentin P, Waultier S, et al. Technologist radiation exposure in routine clinical practice with ${ }^{18}$ F-FDG PET. J Nucl Med Technol. 2005;33: $175-179$.

17. Deloar HM, Fujiwara T, Shidahara M, Nakamura T, Yamadera A, Itoh M. Internal absorbed dose estimation by a TLD method for ${ }^{18}$ F-FDG and comparison with the dose estimates from whole body PET. Phys Med Biol. 1999;44:595-606.
18. Goldman LW. Principles of CT: radiation dose and image quality. J Nucl Med Technol. 2007;35:213-225.

19. International Commission on Radiological Protection (ICRP). 1990 Recommendations of the International Commission on Radiological Protection. ICRP publication 60. New York, NY: Pergamon Press; 1991.

20. International Commission on Radiological Protection (ICRP). 2007 recommendations of the International Commission on Radiological Protection. ICRP publication 103. Ann ICRP. 2007;37:1-332.

21. Snyder WS, Ford MR, Warner GG, Watson SB. "S" absorbed dose per unit cumulated activity for selected radionuclides and organs (part 1). MIRD pamphlet 11. New York, NY: the Society of Nuclear Medicine; 1975.

22. Shope TB, Gagne RM, Johnson GC. A method for describing the dose delivered by transmission x-ray computed tomography. Med Phys. 1981;8:488-495.

23. International Commission on Radiation Units and Measurements (ICRU). Photon, electron, proton and neutron interaction data for body tissues. ICRU report 46. Bethesda, MD: ICRU; 1992.

24. International Commission on Radiological Protection (ICRP). Managing patient dose in multi-detector computed tomography (MDCT). ICRP publication 102. Ann ICRP. 2007;37:1-9.

25. International Commission on Radiological Protection (ICRP). Managing Patient Dose in Computed Tomography. ICRP publication 87. Ottawa, Ontario, Canada: ICRP; 2001. 